\title{
NEWS
}

\section{New plastic recycling technology}

\author{
John A. Glaser ${ }^{1}$
}

Received: 10 December 2016/Accepted: 13 December 2016/Published online: 30 January 2017

(C) Springer-Verlag Berlin Heidelberg (outside the USA) 2017

Greater than $60 \%$ of the total plastic content of municipal solid waste is comprised of polyolefins (low-density, highdensity, and linear polyethylene and polypropylene. Polyethylene (PE) is the largest volume component but presents a challenge due to the absence of low-energy degradation processes. A recent research report offers a candidate

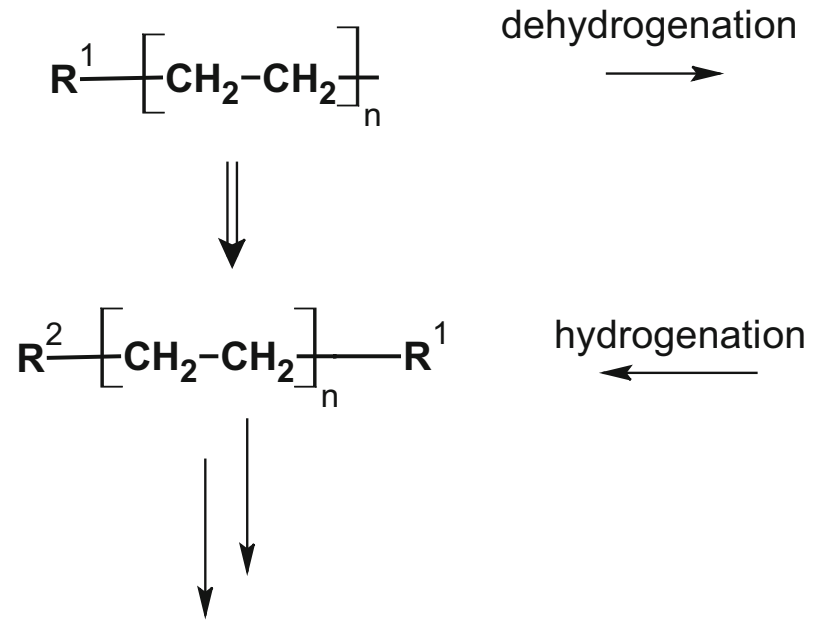

Waxes and liquid fuels

Disclaimer: The views expressed in this article are those of the author and do not necessarily represent the views or policies of the US Environmental Protection Agency.

John A. Glaser

Glaser.John@epa.gov

1 US Environmental Protection Agency, National Risk Management Research Laboratory, 26 W King Dr, Cincinnati, OH 45268, USA chemistry to fill the needs of a new process. Utilizing tandem catalytic cross-alkane metathesis (CAM) process, researchers have shown that polyethylenes can be degraded under mild reaction conditions using an iridium catalyst as outlined in the following scheme:
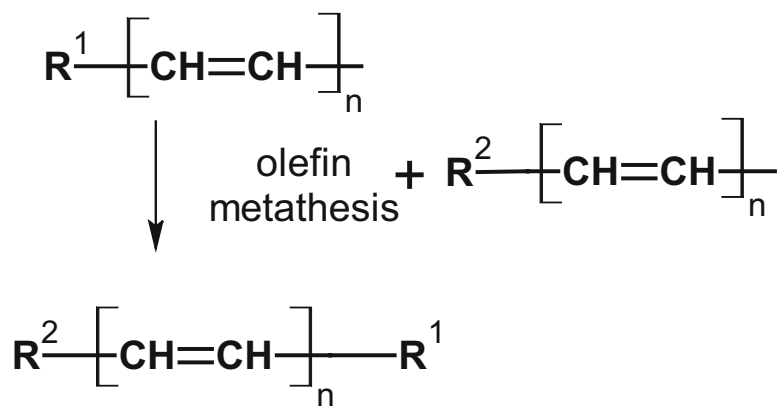

Using a sequence of dehydrogenation/hydrogenation reactions conducted by two catalysts, the CAM process leads to waxes and liquid fuels as recycled products. The alkane dehydrogenation catalyst abstracts hydrogen from PE and a low molecular weight alkane to form a catalytic intermediate species $\left(\mathrm{Ir}-\mathrm{H}_{2}\right)$ and an unsaturated intermediate. Olefin metathesis follows by employing a catalyst to combine the alkenes, which are then hydrogenated to products, and completes the decomposition of the PE chain. The recycling of the reaction sequence leads to the formation of liquid fuels and 
waxes from PE under mild conditions. The low molecular weight alkane component of the reaction mixture affords low viscosity conditions, which support mass and heat transfer accompanying the reaction. The new reaction conditions are mild and offer product control with high efficiency. Catalyst compatibility was found to be broad when tested against the variability of polymeric feeds. This new decomposition process for PE begins to provide useful technology to convert plastic waste to useful and valuable chemical products.

Sci Adv 2016, 2, 6. doi: 10.1126/sciadv.1501591.

\section{Chemical design and processing}

An engineering analysis perspective presents how processcentered and product-centered synthetic strategies as classifications describe the design of chemical-based products. A process systems viewpoint is employed to evaluate both classifications. Chemical product design focusses on a molecular target(s) having a set of desired properties and functions satisfying the desired product characteristics. Chemical process design concentrates on the development of practical technology to form products having desired properties and functionality via a series of processing steps from raw materials. Systematic model-based techniques for process design have been applied to optimization, operation, and control, and corresponding developments that are required to advance product design. Identification of contributions for each classification can be displayed on timeline diagrams. The multidisciplinary nature of new design targets requires sustainable, innovative, and novel solution strategies capable of answering the lack of data required for model development, the incorporation of multiscale options, and reliability. The integration of an experimental approach with a dedicated model is presented to lead to systematic computer-aided framework with built-in design templates from a process perspective. A variety of product-based programs has been developed by chemists to aid the direction of synthetic endeavors. The extension of these efforts beyond bench scale needs more support and extension of research.

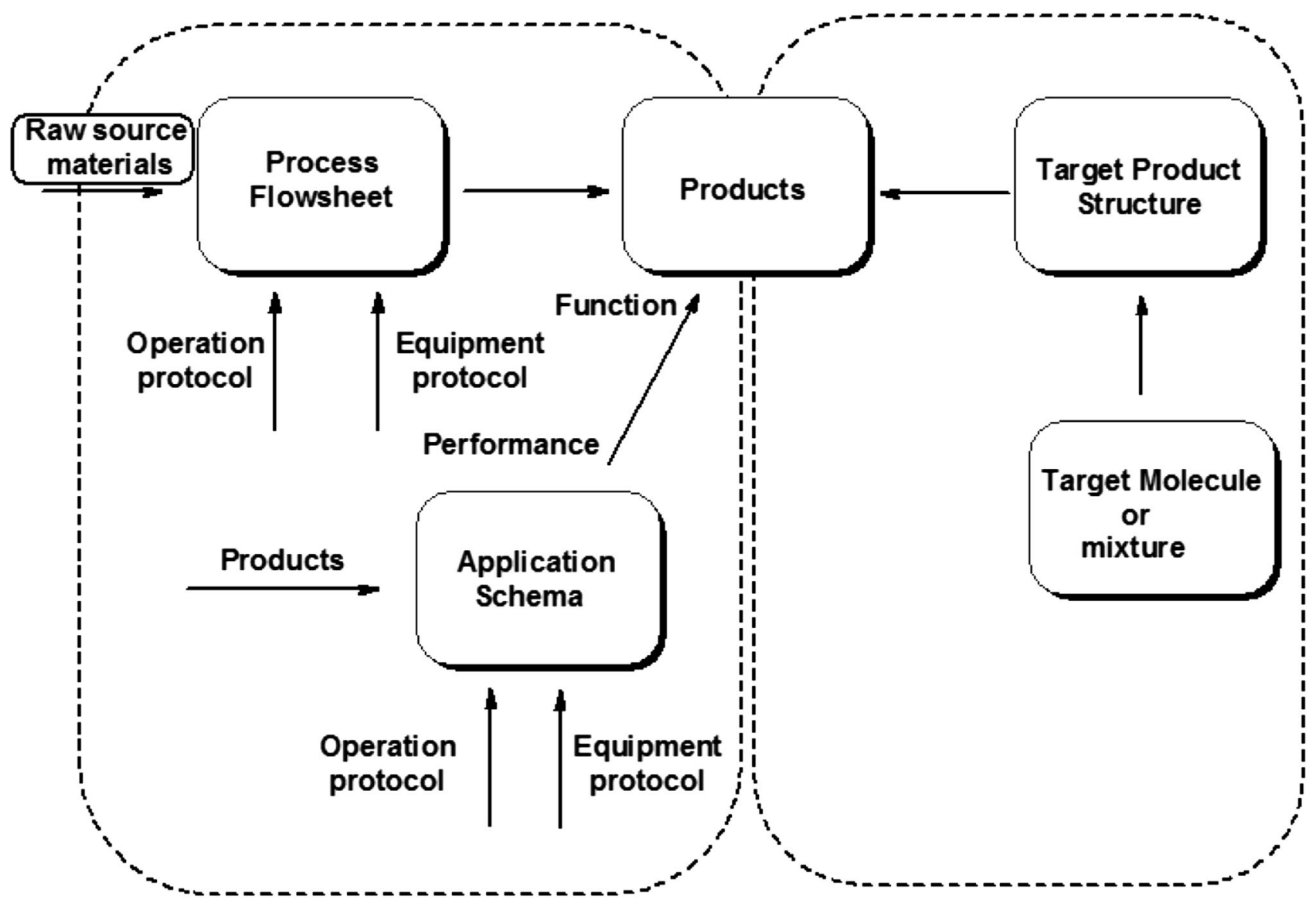

Process Design 
To be commercially competitive, the design for the product and process require optimization. Modern society requires a broad range of products based on chemicals that contribute to societal sustainability. Keys leading to success involve cost, time required to reach market, and product functions, application to small commodity molecules, large and macromolecules, and chemicals selected for functionaluse purposes. An array of risk factors is extensive ranging from raw material availability to product function relationships. The search for chemicals-based manufacturing processes and the resources required to produce them continues to look for models and solutions to the myriad challenges facing the chemist and engineer.

Ann Rev Chem Biomol Eng 2016, 7, 557-582; Comput. Chem. Eng. 2015, 81:70-79; 2015, 81:218-44; Comput. Aided Chem. Eng. 2015, 37:2093-98.

\section{Antibiotic-resistant microbes found in sewage line break}

A 2014 sewer line break in St Petersburg, FL, leading to a discharge of untreated waste water and solids was found to contain disease-causing microbes exhibiting antibiotic resistance characteristics. At flow rates of 500 $\mathrm{gal} / \mathrm{min}$, the raw sewage invaded populated neighborhoods of St Petersburg and ultimately flowed into Boca Ciega Bay. The broken 20-inch iron pipe released some 500,000 gallons into an area of residential homes. The initial flow was redirected by supplemental plumbing. The raw sewage released through the break was found to contain dangerous antibiotic-resistant bacterial strains. Specifically, vancomycin-resistant bacteria were identified in the fecal and sewage pollution from this break. As a "last-resort" antibiotic, vancomycin is used or relied on in conditions where infections have not responded to other pharmaceutical therapeutics. Vancomycin-resistant microbes are known in the hospital environment, but persistence in the raw sewage after two weeks is alarming. Such "superbugs" in the environment can contribute to the spread of antibiotic resistance and concomitant loss of reliable "last-resort" antibiotic resistance therapeutic tools.

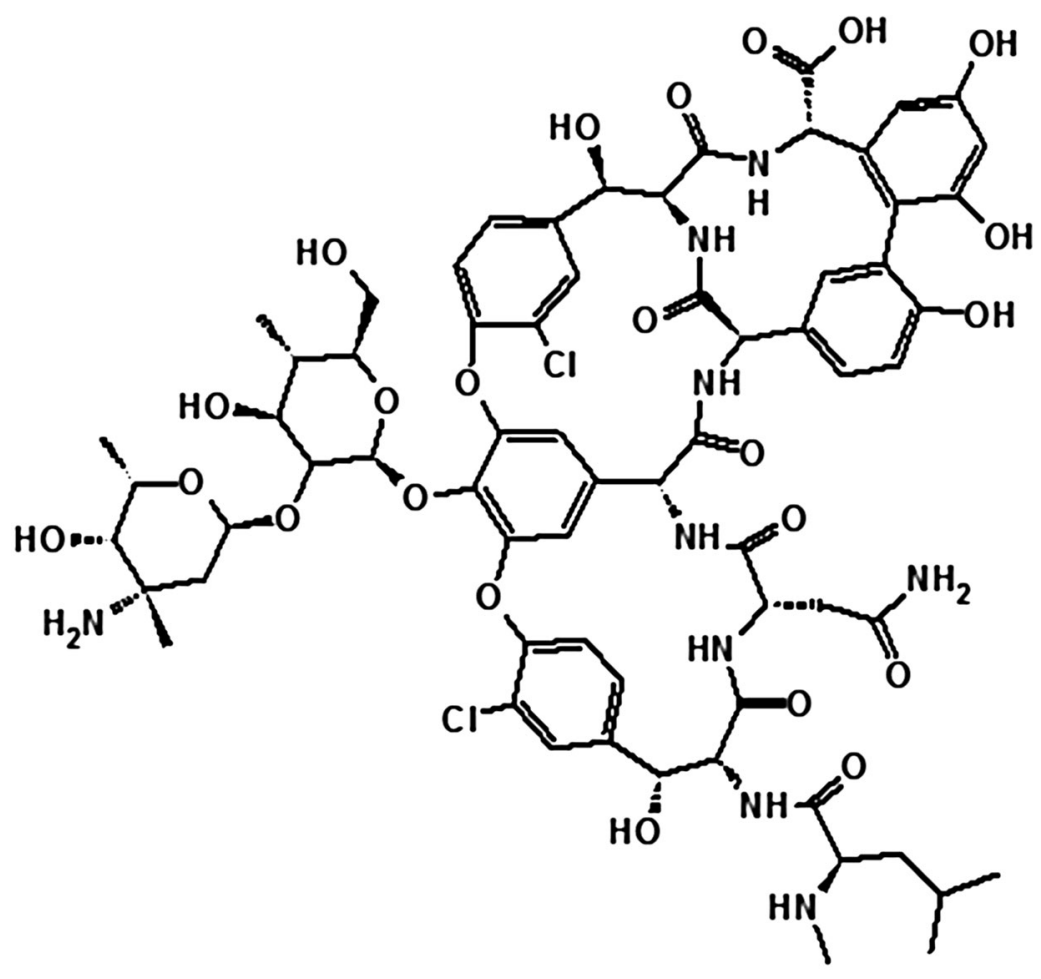

Vancomycin 
Appl. Environ. Microbiol. 2016, doi:10.1128/AEM. 01927-16.

\section{Municipal waste to renewable natural gas}

The renewable waste intelligence recently released a report The Municipal Challenge: Converting Organic Waste Streams into Renewable Natural Gas Through Anaerobic Digestion in which four municipal department managers were interviewed to learn what innovative management success could be achieved to assist the pursuit of municipal waste gasification to form biogas (a 50:50 mixture of methane and carbon dioxide).

\section{Biomass $\longrightarrow \mathrm{CH}_{4}$}

The report used a series of specified topics: "what types of projects municipalities are pursuing to meet local waste management and renewable energy targets?, the unique challenges and opportunities they face when pursuing and developing biogas and biomethane projects, the partnering process and selection criteria, how finance was structured and secured for different types of projects, and how they mitigate against project risk throughout the project lifecycle" to structure the inquiries. System managers were interviewed, and they revealed a range of solutions exemplified by how municipalities can formulate imaginative programs to implement and extend the use of gasification. The utility of government subsidy schemes and the involvement of the private sector through appropriate strategic partnerships were found to be fundamental components to these undertakings as a readily available and largely untapped source of renewable fuels.

http://1.renewable-waste.com/LP=13418?utm_campaign= 4748\%2026JUL16\%20TA\&utm_medium=email\&utm_ source=Eloqua\&elqTrackId=b8a6f1c2e59147a7ae77bc745d b0277a\&elq=441622fa029c4281bd5ff35763688d1f\&elqaid= 20164\&elqat=1\&elqCampaignId=8974.

\section{Climate change to US population}

The Yale Program on Climate Change Communication and the George Mason University Center for Climate Change Communication have recently published a 51-page report, Climate Change in the American Mind: March, 2016 showing the results of analysis of survey results targeting US citizens. The idea of global warming has increased by $7 \%$ in the American population since the spring of 2015. Cumulatively, some $70 \%$ admit to the reality of global warming. Concern for the problems associate with climate warming was shown to rise in an increase of $5 \%$ over the 2015 estimate. There are a majority of population components finding the issue and its consequences to be "somewhat" or "very" upsetting. Increased concern was found for the effects of global warming for the personal health of people of developing countries, and for future generations. A strong support for the education of youth concerning global warming and its consequences can be found in the results of the survey.

http://climatecommunication.yale.edu/wp-content/uploads/ 2016/06/Climate-Change-American-Mind-March-2016FINAL.pdf.

\section{Corporate sustainability}

The United Nations Global Compact has recently released a 48-page report: Guide to Corporate Sustainability, which asks business to strive toward the framework of five defining features of corporate sustainability as part of the Global Compact's mission to foster global sustainability. Features of principled business asserted are: strengthen society, commitment to leadership, report progress, and ensure action at the local level, which are considered the cornerstones of corporate sustainability. The importance of these features is underscored as imperative to business operations today since they embody long-term corporate success and provide markets that deliver value across society. Businesses are called to operate responsibly in alignment the with universal principles and undertake activities supportive of the society around them. It is anticipated the corporate focus on sustainability can be infused deeply into the DNA of company operations through the commitment to report at the highest corporate levels using annual reporting of their efforts and a display of their leadership by engaging with local populations where the company has a production presence.

Global Compact is a voluntary initiative based on CEO commitments to implement universal sustainability principles and to undertake organization of corporate interests in social responsibility and sustainability. The UN Global Compact is designed to assist and inspire businesses at the global level to embrace socially responsible policies and sustainability with information related to their implementation. The areas of human rights, labor, environment, and anti-corruption provide the objectives to formulate a principle-based framework for business. The UN Global Compact claims to be an initiative with a membership of 13,000 corporate participants and other stakeholders from more than 170 countries.

https://www.unglobalcompact.org/docs/publications/UN_ Global_Compact_Guide_to_Corporate_Sustainability.pdf. 


\section{Displacement of starch-converting enzymes} by biotech maize

Nature has utilized enzymes as means to conduct catalytic chemistry required to sustain the biological functioning of living matter. Such catalysts are attractive for the advancement of current biotechnology applications ranging from biomass conversions to industrial chemical synthesis. A significant contributor to this area of technology developments is the conversion of corn/maize to fuel ethanol by hydrolysis of starch and fermentation of the resulting sugars.

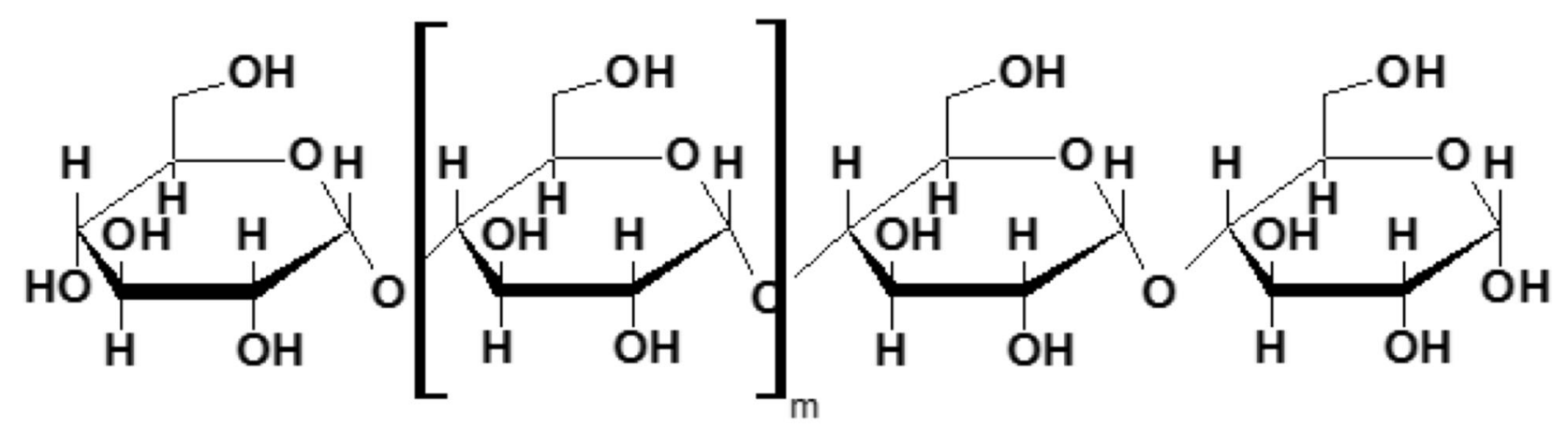<smiles></smiles><smiles>OC[C@H](O)C(O)O</smiles><smiles>CC1CC(O)C(O)OC1CO</smiles>

\section{Amylase Facilitated Starch Hydrolysis}


While $\alpha$-amylase has been used for starch hydrolysis as a component of the process scheme beginning with the non-modified corn/maize, this adds an additional processing step, by incorporating the $\alpha$-amylase gene in the corn/maize, the ethanol producers can reduce processing time and enzyme costs. domestic product GDP. The US rank was enhanced by high scores for new metrics used in the 2016 analysis. Improvements to energy intensity, or energy use per dollar of GDP boosted the US position. Scoring methodology apportions more weight to policy actions benefited the US rating.

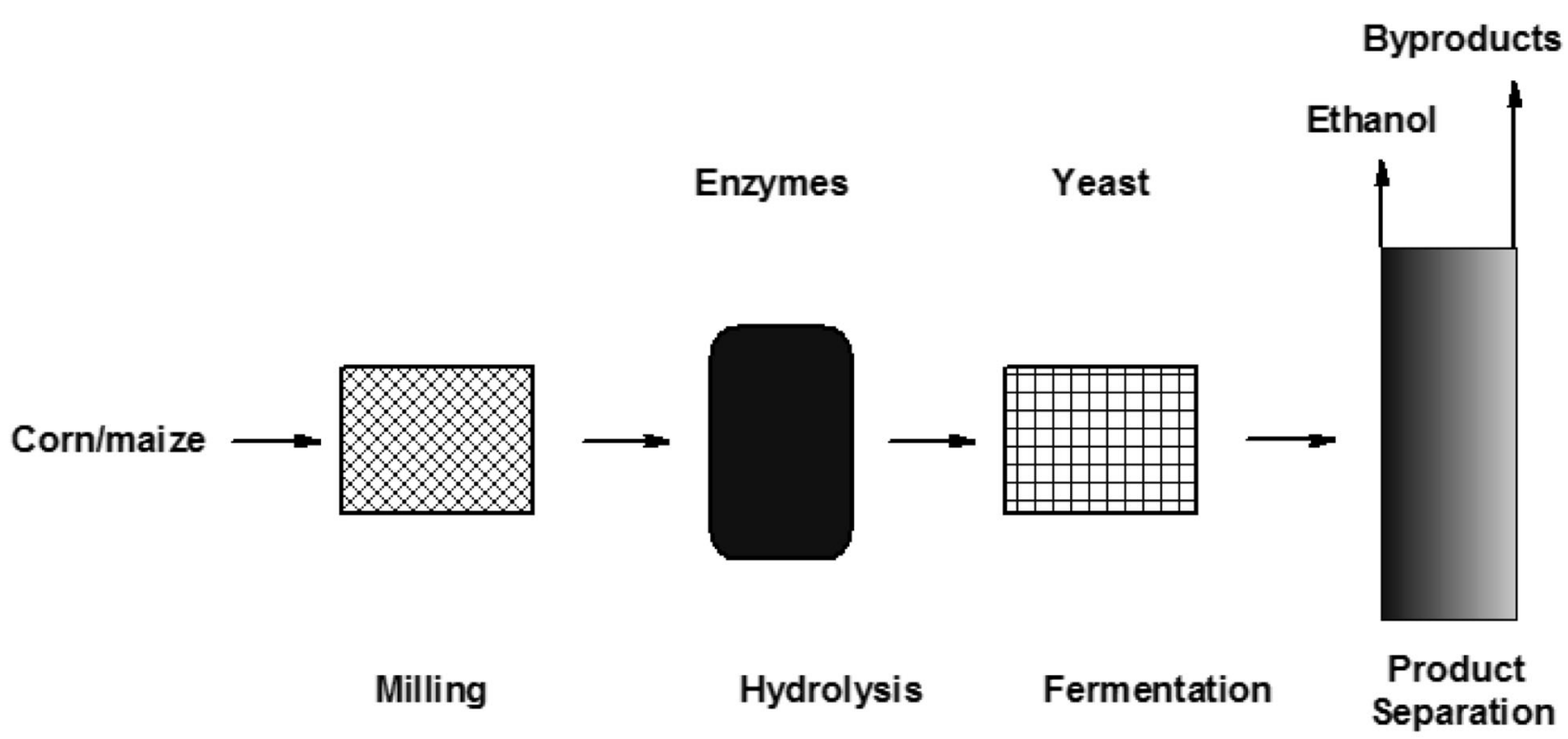

\section{Corn Conversion Technology Schematic}

The new corn variety was introduced in 2011 in the USA. Currently, some 20 ethanol plants employ corn varieties with this trait as the process feed. The corn growers pay a premium of $\$ 0.40 /$ bushel for the new trait expressed in the new corn/maize varieties.

Chem Engin News 2016, 94, 29, 13.

\section{International energy efficiency scorecard}

The non-profit American Council for an Energy-Efficient Economy has recently released the new assessment of international energy efficiency in a 125-page report, 2016 International Energy Efficiency Scorecard. The report finds Germany to continue leading the world in energy efficiency. Italy and Japan are tied for second place followed by France, and the UK. Eight nations: Indonesia, Netherlands, Poland, Saudi Arabia, South Africa, Taiwan, Thailand, and Turkey are included in the rankings this year. The USA was found to move from the 13th position in 2014 to the 8th slot in 2016. The countries included in the scorecard account for $75 \%$ of the global energy consumed and more than $80 \%$ of the world's gross
Thirty-five policy and performance metrics were used to assess each country across four categories: buildings, industry, transportation, and overall national energy efficiency efforts. Each nation was rated using the four categories and ranked with a score. Different categories played unique roles for each of the participating countries. The analysis and individual country scores are made available for intercomparison and contrast within the report.

Energy efficiency was found to be the lowest cost approach to providing for new energy demand. The investment for energy efficiency required to meet the challenge of new energy demand needs support from benign policies and can reduce pollution, conserve energy resources, save citizen monies, and shrink fossil energy import dependence.

Efforts promoting energy efficiency were found to miss the needs of growing energy demand largely due to underutilization even though there are established multiple benefits and energy source replacement can be met through aggressive energy efficiency promotion. The US was found to be significantly lacking in the pursuit of these goals. Enunciated policies establishing energy targets could enable the US to reach its stipulated energy goals. Other 
operation improvements for the USA were energy conservation efforts such as passenger fuel economy, building energy requirements, appliance labeling, water use efficiency controls, and freight energy efficiency as targets for improvement.

http://aceee.org/research-report/e1602.

http://westernvaluesproject.org/why-coal-mines-closespoiler-its-the-economy.

\section{Flow process solutions for pharma}

Flow technologies applied to the preparation of fine chemicals have become a very popular option. Multipurpose batch or semi-batch reactors dominate production in the pharmaceutical industry without many examples of this emerging technology. New technology development has largely been confined to academic pursuits despite the pressing demands for chiral and highly functionalized compounds. Microreactors forming a continuous flow system offer significant advantages accrued from the high surface to volume ratios (related to small dimensions), laminar flow conditions, improved mass and heat transfer coefficients, and enhanced volumetric productivity. Inline analytical monitoring of a continuous flow process offers greater control and assists isolation and purification steps.

Developmental schema for continuous flow synthetic methodologies have been shown to be quite versatile by involving components such as microwave irradiation, supported reagents or catalysts, photochemistry, inductive heating, electrochemistry, new solvent systems, 3D printing, or microreactor technology. Fully automated processes have been developed to demonstrate that enhanced process efficiency and sustainability are attainable. This review explores some 28 sequences demonstrating how differing synthetic complexity for pharmaceutical products could be designed for flow synthetic system application.

A scheme depicting the synthesis of diphenylamine hydrochloride found in Benadryl, ZZZquil, Tylenol, PM and Unisom shows the organizational simplicity of a flow process procedure. In contrast to batch synthetic routes, this flow process offers production time and purification step reduction, and reduced waste. The yearly demand of this pharmaceutical compound exceeds 100 tons/year.

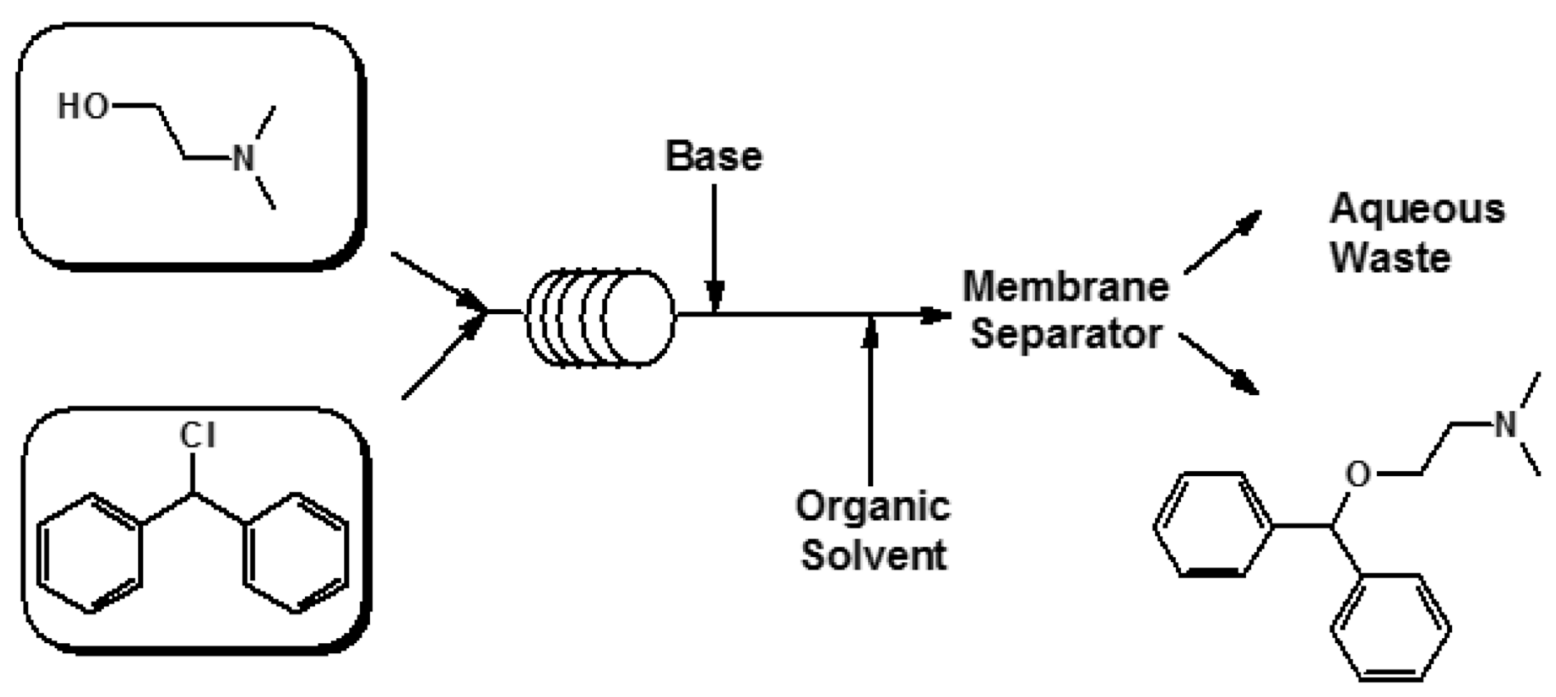

Diphenhydramine hydrochloride 
This review integrates within the overall discussion a framework organizing different types of continuous flow systems. The four reactor types of these flow systems are made of type I (no catalyst), type II (supported reagents), type III (homogeneous catalyst), and type IV (heterogeneous catalyst). Combination of these features can lead to fully automated process development designed to optimize and provide increased efficiency and enhanced sustainability where possible. Flow conditions for manufacturing organic intermediates can be used to conduct synthetic steps in which the reaction conditions could not be considered for bulk synthesis system due to safety considerations required to conduct synthetic operations with minimum risk. Continuous flow technologies are attractive for possible features available to the design of an industrial process.

Org. Process Res. Dev. 2016, 20, 2-25.

\section{Environmental crime}

The illegal wildlife trade has been the target of increasing attention in the news media and has been exemplified by the wanton of large animals such as elephants and rhinos. Mass extinctions of iconic wild species at the verge of loss deprive certain countries of their environmental fauna. Criminal activity has been expanded to a spectrum of activities involving waste, pollutant chemicals, conflict minerals, timber including other forest products, and illegal seafood harvest. These crimes are the subject of a recent 108-page UNEP-INIPOL Rapid Response Report: The Rise of Environmental Crime. The growth rate of environmental crimes is astonishing as categorized by this report. The criminal reach has become diversified and is recognized as the fourth largest crime category across the globe growing at a rate of 2-3 times that of the world economy.

This analysis estimates the loss of natural resources valued at \$91-258 billion US are taken by criminals annually. The loss adversely affects countries through revenue and developmental opportunity reductions. The crime leads to global losses in terms of resource support for future generations and general health at a scale not previously encountered. These limitations subvert the achievement of sustainable development goals. Peace is more difficult to achieve due to the effects of environmental crime.

Environmental crimes encompass illegal activities such as the smuggling of ozone depleting substances, banned mining practices, and waste abandonment of items including chemicals, natural resource destruction as in fishery, forestry preservation, and wildlife trade. Illegal mining operations are often characterized as presenting severe environmental damage through the use of heavy metal extraction technology that leads to pollution. This form of crime offers financial means to support terrorist activities through natural resources, with the undesirable effects of such illegal activities and the collateral environmental impacts. Due to its current global prominence, environmental crime is attracting the worldwide attention of efforts to combat its occurrence, the exploitation of natural resources, and the accompanying negative environmental effects. Controls are anticipated to be possible through the use of cross-sectional and transborder cooperation/collaboration which offer the basis for the formation of strong weapons targeting environmental crime.

http://unep.org/documents/itw/environmental_crimes. pdf.

\section{Plastics rethinking}

A new 120-page report, The new plastics economy: Rethinking the future of plastics, by McKinsey, the Ellen MacArthur Foundation, and the World Economic Forum, suggests that the application of circular-economy principles to the flow of plastic packaging at a global scale could reshape the economics of plastics for the global economy and assist the solution to environmental protection controls.

For the past 50 years, plastic materials have been integral to the modern economy, which is apparent from the popularity of this material. Through the acceleration of global plastic production, production levels of 311 million metric tons in 2014 have been achieved. Extending the rate of consumption across the next 20 years is projected to reach production levels of 600 metric tons or more.

This increasing quantity of material has provided myriad applications of remarkable practical nature but with a significant environmental cost. Many components of plastic waste are limited to single-use product lives: packaging applications consist of $25 \%$ of the total plastics volume, and this is the equivalent of $95 \%$ of the value of plastic packaging material. Estimates of $\$ 80-\$ 210$ billion per year lost to the economy due to these conditions. The expected useful life of plastic materials is approximately a year or less, but the lifetime is extended to centuries through its role as environmental pollution.

The application of circular-economy principles to global plastic packaging flows suggests that the plastics economy could be restructured through drastically reducing negative consequences. One solution focusses on the ocean pollution by plastics that could be solved through the implementation of effective and efficient waste-collection systems. Annual plastic ocean pollution is estimated at some 8 million metric tons. The report asserts that past attempts to combat these circumstances were subpar and fragmented. The report tries 
to enlist the plastic industry by suggesting that a significant option for action calls to adopt a positive spiral of value capture, and stronger after-use plastics economy, which can translate into improved environmental conditions.

In Europe, it was found that $53 \%$ of plastic packaging could be recycled "ecoefficiently." This accomplishment offers the clear identification of recycling opportunities that must be mustered into service to aid the environment. The proposed new plastics economy offers attractive options available for country adoption as part of the global value chain. New packaging designs targeted to material design, new technology, and acceptance of new formats and systems could enable the move to new global value chains. To ensure the projected accomplishments, a generally accepted coordinating entity would be invaluable to drive this global program to the formulation of a global plastics code of behavior through the use of demonstrations and large-scale evaluations. The report offers a fundamentally new approach to the design and manufacture of plastic packaging and plastics in general with a desired outcome of transforming the global plastic packaging materials lifecycle.

http://www.mckinsey.com/business-functions/sustain ability-and-resource-productivity/our-insights/rethinking-thefuture-of-plastics?cid=other-eml-cls-mip-mck-oth-1606.

\section{Climate change World Heritage Sites and the national parks}

A recent 108-page report, World Heritage and Tourism in a Changing Climate published by United Nations Environment Programme (UNEP), United Nations Educational, Scientific and Cultural Organization, and Union of Concerned Scientists, offers an overview of climate change impacts on vulnerable heritage sites and implications related to tourism. Site management issues such as poor visitor access, threats, and stresses were found to heighten the climate change effects. The security of World Heritage Sites can be envisioned by improving a heightened role for tourism.

By employing World Heritage site as case studies from sites across the globe as iconic tourist destinations, the report confirms the future effects of the current climatedriven changes. The threats are identified for what they represent to the site's outstanding universal value (OUV), integrity, and authenticity, and extension to the dependence of economies and communities on tourism. The case studies were selected for the diversity of types of natural and cultural heritage, geographic location, and tourism appeal. The selected site offers a wide range of climate impacts and has technical evidence available to support these directions. The studied sites were found in 29 countries and involve 31 World Heritage sites. The analytical treatment of the sites was presented as referenced case studies and others with briefer analysis. Common findings elicited from the case studies provide an understanding of the relationships World Heritage sites related to climate change and tourism.

Glacier loss, sea level rise, and wildfires present threats to the 412 national parks and monuments that have become part of the US heritage. Closely allied to this analysis is the recognition of the 100th anniversary of the founding of the US Parks Service. For example, the Statue of Liberty has been deemed to be at "high exposure" risk in severe weather-related systems. Areas close to the coast are subject to sea-rise effects such as Jamestown, Virginia where the land may be beyond rescue. Forests will be altered as the temperature rises. The giant sequoia trees in 65 remaining groves could be lost due to the anticipated warmer, drier climate. Animals on these national preserves will be adversely affected through changes of the food chain and related ecological fluctuations. To the tourist, climate change is expected to induce general threats across the park system that may be of an existential nature.

http://whc.unesco.org/en/activities/883/.

https://www.theguardian.com/environment/2016/aug/22/ climate-change-national-parks-threat.

\section{New journal}

A new Current Opinion journal, Current Opinion in Green and Sustainable Chemistry, is a soon-to-be released addition to the expanding literature concerned with this attractive field of chemistry. The focused information of these collections is directed to meet the needs of specialists who face a continuing problem of maintaining an up-todate knowledge of specific scientific fields against recognition that it is increasingly difficult to master expanding volume of information published in a subject. In Current Opinion in Green and Sustainable Chemistry, papers are expected to provide the reader through the use of systematic writing to identify and analyze the newest and most significant scientific findings of chemistry related to green and sustainable objectives. The new journal is subdivided into sections: mineral and fossil resources and metals, biomass, biofuels and bioenergies, $\mathrm{CO}_{2}$ capture with related chemistry, green solvents, green catalysis, new synthetic methods, photocatalysis, green processes with attendant technologies, renewable energy storage, sustainable recycling of molecules, materials and products, benign by design, supporting new business models, ethics of technology use, legislation and economics developments. A special section will be devoted to hot topics that are expected to change yearly. Journal space devoted to each section will be reflective of its importance. The content will consist of short review articles depicting recent 
developments of a subject area, which emphasize important aspects, deemed important in the author's opinion and annotations to publications in the topic area published during the past year. The new journal should provide a new source of insight into the burgeoning field of publications addressing advances and analysis of green and sustainable chemistry.

http://www.current-opinion.com/journals/current-opinionin-green-and-sustainable-chemistry/. 